\title{
Vanwaar die eenhoring in Bybelvertalings?
}

\author{
L.F. Schulze \\ Departement Dogmatiek en Ekklesiologie \\ Potchefstroomse Universiteit vir $\mathrm{CHO}$ \\ POTCHEFSTROOM
}

\begin{abstract}
Luther's translation of Psalm 22:22 reads: "Deliver me from the unicoms" (erretie mich von den Einhômem). This translation arouses curiosity for it is common knowledge that the unicom has never existed but yet flgures as a prominent symbol of the New Age. Besides, the Hebrew word means antelope, buffalo, or wild bull. The question thus arises why the Hcbrew re'em was translated by Luther with unicom While the official Dutch translation of 16.33 (Statenvertaling, translated according to the title page from the original languages) gives the same translation as Luther, the obvious deduction was that the unicorn was such a powerful symbol in Itah century Europe that it slipped into the Bible translations. However, Calvin, tending even less than Luther to allegory and non-literal interpretation, also mentions the unicons in his commentary on Psalm 22:22. This renders Jerome's Vulgate suspect and, indeed, the Vulgate translates the Hebrew' word with unicoms. The next stop was the translation of the Septuagint, which reads monokeros. In this way the cultural background as a possible explanation of this translation shifted fom the Ith century to the first centuries B.C.
\end{abstract}

\section{INLEIDING}

Die eenhoring is "een dier uit de fabelwereld" (Anon., 1957:548). Tog het 'n bekende geleerde soos J.W. von Müller nog in die vorige eeu in sy Das Einhorn vom geschichtlichen und naturwissenschaftlichen Standpunkt (1853) die bestaan van die eenhoring probeer bewys. Op sy poging is daar egter gegronde en vernietigende kritiek uitgespreek (Anon., 1890:382). Daarom word dit tans aanvaar dat die eenhoring nie bestaan nie en nooit bestaan het nie.

Tog duik die eenhoring met sy "gedaante van 'n perd met 'n kenbaard, gesplete hoewe, pluimstert en 'n gedraaide, regte horing wat op die voorkop sit" (Anon., 1972:642) in ons tyd weer op as 'n belangrike simbool wat die denke van die New Age vertolk. Die profetes van die New Age, Alice Bailey, het reeds in die veertigerjare die eenhoring as belangrike simbool van die nuwe tyd aangewys (Cumbey, aangehaal deur Livesey, 1988:146). Vir die aanhangers van die New Age is die eenhoring simbool van krag (wat die ou, bestaande en uitgediende orde vernietig) en tegelyk simbool van persoonlike

1 My opregte dank aan prof. H.F. van Rooy en my vrou lta, wat my nuuskicrighcid oor die cenhoring gedecl en my van waardevolle Ou-Testamentiese en kunshistoricse gegewens en literatuur voorsien het. 
en wêreldomvattende transformasie - 'n krag wat vernietig en uit die afbraak die nuwe te voorskyn bring (vgl. De la Guerre, 1991: 80-83). Die eenhoring kan in skilderye van sommige hedendaagse Suid-Afrikaanse kunstenaars gesien word en dit word ook kommersieel in die vorm van kinderspeelgoed versprei.

Teen bogenoemde agtergrond vryf 'n mens sy oë 'n keer of twee wanneer hy Luther se vertaling (1522) van Psalm 22:22 lees: ... errette mich von den Einhörnern. Die Afrikaanse vertalings praat tog meer verstaanbare taal: die horings van die buffels (1953) of die horings van die wilde beeste (1983). Die vraag ontstaan waar Luther aan die fabelagtige eenhorings kom. Die vraag word dringender wanneer dit blyk dat die King James Version of die Authorized Version van 1611 (vgl. Isaacs, 1940:203, 318) en die Statevertaling (1633) óók van eenhorings praat.

\section{PROBLEEMSTELLING}

Kan Timmers (1985:146) se stelling dat die eenhoring ook in die Bybel voorkom, kritiekloos aanvaar word? Hiermee saam gaan die vraag of die Bybelvertalers die eenhoring as fabeldier beskou en as sodanig in die vertalings ingedra het.

Die antwoorde op bogenoemde vrae bied oënskynlik weinig méér as 'n moontlike oplossing van 'n klein vertalingsprobleem en dra die wetenskaplik onsensasionele aard van (in Duitse terme) 'n Kleinforschung. Op sigself is dit van weinig akademiese belang. Die feit dat aanhangers van die New Age egter prominensie aan die eenhoring as simbool verleen, gee aan die antwoord op bogenoemde vrae 'n onverwagse eksistensiële aard. Met hulle eklektiese werkwyse en sinkretistiese ideaal van één wêreldgodsdiens kan New Age-aanhangers immers hulle gebruik van die eenhoringsimbool ook 'Bybels begrond' en argelose Christene verwar. Daarom het die antwoord op die bogenoemde vrae ook betekenis vir gelowiges vandag. Die vraag is immers of die Bybel dieselfde taal van 'n fabelagtige eenhoring as die New Age praat.

Om hierdie vrae te beantwoord sal eerstens bepaal moet word wat die betekenis is van die Hebreeuse woord wat in Psalm 22:22 met eenhoring vertaal word, en tweedens wat die oorspronklike bron vir die vertaling is en watter kontekstuele, literêre en/of kultuurhistoriese omstandighede tot die vertaling aanleiding gegee het.

\section{BEGRENSING}

Die voorkoms van die eenhoring in die Westerse kultuur bied 'n interessante studieveld vir die kultuurhistorikus om die betekenisverandering van 'n simbool na te vors. Betekenisveranderings in die eenhoring as simbool het nie slegs diakronies plaasgevind nie maar kan ook sinchronies aangedui word. Laasgenoemde betekenisverandering kom voor onder andere vanweë die kerkvaders se neiging tot allegorisering. Allegori- 
sering is niks anders nie as ' $n$ twyfelagtige metode van eksegese, waardeur die letterlike betekenis van die Skrif in honderd en een rigtings geïnterpreteer kan word. Interpretasie van die Skrif is egter geen uitleg van die Skrif nie (Stoker, 1935:27-33). As gevolg van hulle allegoriese interpretasie kon die eenhoring by die kerkvaders die volgende verskillende en selfs kontradiktoriese betekenisse he: simbool van die kruis (Justinus); simbool van Christus (Basilius, Origenes); simbool van patriarge, profete en Christene (Athanasius); simbool van die eenheid van die geloof (Augustinus, Lombardus); simbool van die Jode en die bose magte (Augustinus, Gregorius die Grote) (vgl. Brandenburg, 1959:847-851).

As gevolg van die Physiologus (ontstaan ong. 200 n.C. in Alexandrieë, skrywer onbekend) se vermelding dat die ontembare eenhoring alleen deur ' $n$ maagd aangelok en gevang kan word, word die eenhoring in die later Middeleeue simbool van Maria (soms ook van Christus) en van kuisheid in die algemeen (Dijkstra, 1982:77,91; Einhorn, 1981:1247; Ferguson, 1961:26,128; afb. van maagd en eenhoring in Anon., 1957:548; Anon., 1972:642; Brandenburg, 1959:857,858; Dijkstra, 1982:77; Wittkower, 1976:77,78).

Die simboliek van die eenhoring word egter in hierdie artikel buite rekening gelaat, behalwe in soverre die bekendheid met 'n bepaalde simboliese verklaring in 'n bepaalde tyd moontlik lig op 'n tydgenootlike vertaling van Psalm 22:22 kan werp.

\section{DIE BETEKENIS VAN IIE HEBREEUSE WOORD}

Daar is blykbaar 'n mate van onsekerheid oor wat die Hebreeuse woord remim (mv. van re'em of rem) beteken. Davidson (1945, s.v. ra'am) meld dat Bochart die woord met oryx (antiloop, wildsbok) vertaal, terwyl Schultens, Gesenius en Lee buffel verkies. In meer resente artikels word die wildsbok (onx) as korrekte betekenis van die Hebreeuse woord aangewys (Clark, 1984:66-67), terwyl Klotz die wildsbok, wilde os of renoster as betekenismoontlikhede voorhou (1979:213-215).

Ook ander woordeboeke en kommentare soek die betekenis van die Hebreeuse woord in dieselfde rigting.

Gordon (1965:481) meld dat die term in Ugaritiese tekste (veral in mitologiese tekste) redelik bekend is en ook in Akkadies voorkom en meen dat dit buffel beteken.

Van Uchelen (1971:156) sê dat die term osse beteken, wat in die Statevertaling met die fabelagtige eenhoring vertaal word. Die prototipe was waarskynlik die stier (bul) wat op die Babiloniese Ishtarpoort afgebeeld is en sinnebeeld van die vreeswekkende stormgod Adad was (vgl. ook Hess, 1915:121). McCallough (1955:121) vertaal in sy kommentaar op Psalm 22:22 die Hebreeuse woord met wilde stier (bul). Ook Briggs 
(1969:198) meen dat die Hebreeuse woord dui op "the fierce bull of ancient times which has now become extinct".

Eksegetiese gegewens laat ons met wildsbok, buffel of bul. Die eenhoring kom egter nie ter sprake nie. Die vraag bly dus steeds geldig: Waar kom Luther dan aan die eenhoring?

\section{VOORLOPIGE BEREDENERING.}

\subsection{Luther}

'n Aanvanklike hipotese was dat die geniale Luther die vader van die vertaling van die Hebreeuse woord met eenhoring was en dat bepaalde kultuurhistoriese tendense van die Renaissancetyd moontlik die agtergrond hiervoor (sowel as vir die vertalings van die Authorised Version en die Statevertaling) was.

Inderdaad was die simbool van die eenhoring in die Laat Middeleeue en Renaissance baie bekend. Die proses om die eenhoring af te beeld het reeds in die 9 de eeu begin, byvoorbeeld in die Kosmas-manuskrip van die Vatikaan en die Physiologus-manuskrip van Bern (Brandenburg, 1959:857-858, met afb. van lg.). Die afbeeldings vind in die Laat Gotiek en in die kuns van Luther se tyd 'n hoogtepunt. 'n Mooi voorbeeld hiervan is die beroemde muurtapyte getitel La dame à la licome (die dame met die eenhoring), wat omstreeks 1500 gemaak is en in die Cluny-museum in Parys te sien is (Anon., 1972:642, met 'n afb.).

In die afbeeldings sedert die 9de eeu vind ons die eenhoring altyd saam met 'n maagd (Maria) of ' $n$ dame (kuisheid). Die afbeeldings was aanvanklik illustrasies in die verskillende handskrifte van die Physiologus, wat die vangs van die eenhoring deur 'n maagd verhaal. Die illustrasies het die teks se beskrywing van die eenhoring redelik getrou gevolg (vgl. Brandenburg, 1959:858).

Later toon die ikonografie die eenhoring as simbool van Christus. In die Laat Middeleeue word die jag op die eenhoring (verhaal in die Physiologus) dikwels afgebeeld. Dit is ' $n$ allegorie op die aankondiging van die geboorte van Christus, waar die engel Gabriël (die aankondiger) as jagter optree en die eenhoring (Christus) in die skoot van Maria vind (Anon., 1957:548). Die spits horing van die eenhoring word gesien as simbool van die kruis, wat die sonde skadeloos maak (Anon., 1972:642).

Die simbool van die eenhoring as Christus en die verband met Maria pas egter nie in die konteks van Psalm 22 nie. In die Psalm spreek die digter (Dawid) sy benoudheid uit. Hy voel hom van God verlaat (vs. 2) en bid om die redding van sy lewe (vs. 21-22): 


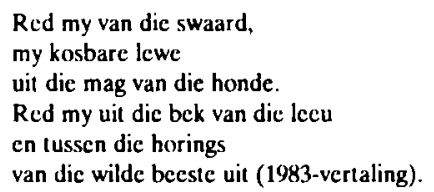

Wanneer Christus aan die kruis self die aanvangswoorde van Psalm 22 op die lippe neem (Matt. 27:46), is dit duidelik dat die lewensbedreigende "wilde beeste" (eenhorings - Luther) nie op Homself kan sien nie en die horing van die eenhoring nie simbool van die kruis kan wees nie.

In die lig van die diskrepansies wat in die vorige twee paragrawe aangetoon is, is dit hoogs onwaarskynlik dat die simboliek van die eenhoring in sy tyd vir Luther die aanleiding kon gewees het om re'em in Psalm 22:22 met eenhorings te vertaal. Luther het hom nie deur populêre voorstellings van sy tyd laat lei nie maar deur 'n bepaalde Bybelteks wat hy vertaal het.

Calvyn se kommentaar op Psalm 22 bevestig dat die aanvanklike hipotese onhoudbaar is. Hy was, nog meer as Luther, wars van alle allegorisering. Tog praat hy ook van eenhorings, maar teken hulle lewensbedreigende mag (1979:377):

By the sword, by the hand of the dog, by the mouth of the lion, and by the homs of the unicoms, he intimales that he was presently exposed to the danger of death, and that in many ways.

Bogenoemde gegewens toon dat Luther en Calvyn die betekenis van die Hebreeus nie meer verstaan het nie maar hulle deur 'n gemeenskaplike, ouer vertaling laat lei het. Dit geld $606 \mathrm{k}$ van die Statevertaling - ten spyte van die feit dat die titelblad vermeld dat die vertaling uit die oorspronklike tale gedoen is.

Die gemeenskaplike ouer vertaling kan deur eliminasie bepaal word. Die Münsterbybel en die vertaling van Olevitanus het ná Luther se vertaling (1522) die lig gesien. Erasmus bied slegs 'n uitgawe van die Nuwe Testament (1516). Gevolglik kom die tradisionele vertaling waarmee Luther en Calvyn bekend was, naamlik die Vulgaat, as bronteks in aanmerking. En die Vulgaat praat in hierdie teks inderdaad van eenhorings; so ook die Psalterium iuxta Hebraeos, wat hier aangehaal word (Vulgaat en Psalter.: Ps. 21:22):

salva me ex ore leonis

ef de comibus unicomium exaudi me.

(Red my uit dic bek van die leeu

en verhoor my uit die horings van die eenhorings.) 


\subsection{Die Vulgaat}

'n Tweede hipotese was dat Hiëronymus se Latynse vertaling beinvloed was deur die geestesklimaat van sy tyd.

In die lig van die grondige studie van Brandenburg (1959:856) blyk hierdie hipotese ook onhoudbaar. Hy stel dit immers kategories dat alles wat in vroeëre literatuur oor die sogenaamde voorstellings van die eenhoring in die Grieks-Romeinse wêreld gesê is, geen fondament het nie. Voorstellings van die eenhoring in die Grieks-Romeinse kultuur is nie bekend nie. Die eenhoring kon ook kwalik in die antieke tyd verskyn het, omdat die voorstelling van die eenhoring nóg in die mitologie en sage, nóg in die volksbewussyn geleef het maar slegs tot die reisliteratuur beperk was (bv. die Indika van Ktesias en die gelykluidende werk van Megasthenes).

Gegewens uit die kunsgeskiedenis bevestig die afwesigheid van die eenhoring in die Griekse, Hellenistiese en Romeinse kuns (vgl. hyvoorbeeld die relevante hoofstukke in Groenewegen-Frankfort en Ashmole, Huyghe, en Strong).

Hierdie gegewens noodsaak ons om na die Septuagint te kyk.

\subsection{Die Septuagint}

By al die onsekerhede oor die ontstaan en oorspronklike vorm van die Septuagint meen Koole (1961:146) dat die volgende met sekerheid gesê kan word: dat die vyf boeke van Moses eerste vertaal is om by die voorlesing van die Tora 'n betroubare weergawe daarvan te hê ( 3 de eeu v.C.); dat die vertaling van die profetiese boeke nie lank daarna gevolg het nie (moontlik omstreeks 200 v.C.); dat die Geskrifte (die digterlike boeke) laaste vertaal is en dat die hele vertaalproses omstreeks 150 v.C. tot afsluiting gekom het. Dit spreek vanself - en is ook duidelik uit die verskillende vertaaltegnieke - dat verskillende vertalers hulle telkens met die werk besig gehou het. Die Septuagint was die produk, nie van 70 Jerusalemse taalgeleerdes soos die twyfelagtige brief van Aristeas vermeld nie, maar van die Alexandrynse Jodendom (Koole, 1961:145,147).

Die Septuagint gebruik die woord monokeros in Psalm 22:22. Aangesien die gebruik van eenhoring nie in ouer bronne (bv. die Targums) opgespoor kon word nie, moet die Septuagint as oorsprong van hierdie vertaling aangemerk word.

Die vraag is nou hoe die vertalers van die Septuagint aan hierdie vertaling gekom het. Was daar kultuurhistoriese gegewens in die Hellenistiese tyd wat lig kan werp op die feit dat ' $n$ fiktiewe dier sy verskyning in Bybelvertalings maak? 


\section{DIE EENHORING IN DIE WESTE}

\subsection{Ktesias van Knidos}

Ktesias van Knidos (omstreeks 400 v.C., lewenstyd verder onbekend - Jacoby, 1922: 2036) was die eerste Griek wat die eenhoring vermeld en die dier beskryf het (Wittkower, 1976:196, verw. 10). Hy was 'n tyd lank lyfarts van koning Artaxerxes II Mnemon van Persië. In 398/397 het hy na Griekeland teruggekeer, waar hy sy Indika geskryf het.

Vroeër het geleerdes (bv. R. Forrer en R. Brown na wie Brandenburg, 1959:854 verwys) vermoed dat Ktesias sy voorstelling van die eenhoring ontleen het aan afbeeldings van Mesopotamiese kuns wat in Persië bekend was. Die afbeelding van oënskynlike eenhorings op Mesopotamiese kleisilinders is egter nie 'n bewys dat Forrer en Brown reg is nie. Teen die hipotese kan ernstige besware ingebring word. Eerstens moet vermeld word dat in die kuns van Mesopotamië gewoonlik die profielaansig van 'n dier getoon word. Gevolglik word die dier met een horing voorgestel, al het hy in werklikheid twee horings. Tweedens sou 'n mens verwag dat, indien dit eenhorings is wat afgebeeld is, hulle bou min of meer sou ooreenstem. Die mees uiteenlopende soorte diere word egter met een horing afgebeeld. Onder hulle word selfs 'n gevleuelde leeu gevind - iets wat met Ktesias se beskrywing van die eenhoring niks te doen het nie (vgl. Brandenburg, 1959: 854-855).

Ktesias beskryf die eenhoring in sy Indika immers as 'n soort wilde esel, so groot soos 'n perd, met 'n wit lyf, rooi kop en donkerblou oë. Op sy voorkop het hy 'n horing van een en 'n half el, wat onder wit, in die middel swart en bo rooi is. Vooraanstaande Indiërs het die horing as drinkbeker gebruik. Die horing besit genesende krag en om uit die horingbeker te drink beskerm teen krampe, epilepsie en vergiftiging. Die dier is vinniger as perde en wildsbokke en teen sy horing is niks bestand nie (Wellmann, 1905: 2114).

Bogenoemde beskrywing lei daartoe om Ktesias se kennis van die eenhoring elders as in die kuns van Mesopotamië te soek. Hy meld nêrens dat hy self op Indiese bodem was nie. Daaruit kan afgelei word dat hy nie die eenhoring in Indië leer ken het nie. Gevolglik moet die omstandighede aan die hof van Artaxerxes in oorweging geneem word.

Uit die geskiedenis is dit bekend dat die stigter van die Persiese ryk, naamlik Cyrus II of Kores (Jes. 44:28), sy magsgebied tot aan die Indusrivier uitgebrei het. Daar was 'n lewendige handel met die Oostelike provinsies en selfs met gebiede anderkant die Indus. In die lig hiervan is dit begryplik dat 'n verskeidenheid jong diere aan koning Artaxerxes te koop aangebied kon word. Bowendien kon seldsame diere deur onder- 
worpe en bevriende Indiese vorste aan die koning as tribuut of blyke van vriendskap aangebied gewees het (Jacoby, 1922:2036).

Gevolglik is dit baie moontlik dat Ktesias aan die hof van Artaxerxes verskillende vreemde diere leer ken het. Hierdie arts uit 'n geslag van medici maak in sy Indika 'n onderskeid tussen die dinge wat hy gehoor het (fabelagtige dinge), en dit wat hy gehoor en gesien het. Hy beskryf die diere wat hy gesien het, byvoorbeeld die olifant wat 'n palmboom ontwortel (vgl. Jacoby, 1922:2036-2037). Die eenhoring wat hy gesien en beskryf het (ook volgens die fabelagtige dinge wat hy gehoor het), was heel moontlik niks anders as die Indiese renoster nie. Wellmann (1905: 2115) betwyfel dit met 'n beroep op Von Müller. Brandenburg (1959:855), Steier (Nashorn in Paulys Realencycl., 16,2:1780 e.v. - 'n bron wat nie toeganklik was nie) en Wittkower (1976:198, verw. 33) toon egter aan dat Ktesias se eenhoring die Indiese renoster was. Die gewig van die argument lê in die feit dat die Indiërs die renosterhoring as genesend en gifafwerend beskou het.

\subsection{Aristoteles}

Sedert Aristoteles (382-322 v.C.) Ktesias se eenhoring in sy dierebeskrywing opgeneem het (vgl. hist. animal. 2.1.18 en de part. animal. 3.2.63), het die geloof in die bestaan van die eenhoring wye aanhang gevind (Einhorn, 1981:1249; Wellmann, 1905:2114; Wittkower, 1976:196-197, verw. 10).

\subsection{Megasthenes}

Naas Ktesias was daar nog 'n ooggetuie wat die eenhoring van Indië beskryf het. Dit was die vrugbare skrywer Megasthenes (ong. 350-290 v.C.), wie se beskrywing van die Indiese geografie en kultuur vir ongeveer 1500 jaar 'n onbetwiste bron sou bly (Wittkower, 1976:47). Megasthenes is teen 303 v.C. deur Seleucus Nicator, erfgenaam van Alexander die Grote se Asiatiese ryk, as gesant na koning Sandracottus (Chandragupta) gestuur. Laasgenoemde het sy verblyf in die teenswoordige Patna, aan die Ganges gehad. Teen 298 of 297 v.C. het hy na Griekeland teruggekeer (Stein, 1931: 231-233).

Megasthenes het ook 'n werk met die titel Indika geskryf. Daarin beskryf hy onder andere die eenhoring. Sy beskrywing is nogal anders as dié van Ktesias: die wilde esel word nou 'n perd met 'n bokkop en olifantpote, terwyl die horing groei tot twee el (Wellmann, 1905:2114).

\subsection{Ander skrywers}

Ander skrywers wat die eenhoring vermeld (w.o. Diodorus Siculus, Strabo, die ouer Plinius, Arrianus, Aelianus en Solinus) het bloot die tradisie waarmee Aristoteles 
begin het, voortgesit: hulle gegewens oor die eenhoring is uit Ktesias en/of Megasthenes oorgeneem. Dit is interessant dat Aelianus en Solinus die eenhoring nie met die renoster verwar het nie (Einhorn, 1981:1249).

Hierdie skrywers leef almal reeds gedurende die eerste eeue van die Christelike jaartelling. Gevolglik kom nie een van hulle in aanmerking as moontlike bron van die Septuagintvertaling nie.

Die moontlike verbinding van Ktesias en Megasthenes met Alexandrië is 'n laaste skakel wat oorbly en ondersoek moet word.

\section{ALEXANDRIë EN DIE SEPTUAGINT}

Ktesias, wat omstreeks 400 v.C. geleef het, kon geen persoonlike kontak met Alexandriê gehad het nie. Die stad is immers eers in 331 v.C. deur Alexander die Grote aangelê (vgl. Schubart, 1950:271).

Die naaste tydgenoot aan die ontstaan van die Vulgaat was Megasthenes. Wanneer hy presies geleef het, is onseker. Stein (1931:231-233) het 330 v.C. as moontlike geboortejaar genoem maar meen self dat dit vroeër (350 v.C.) kon gewees het, omdat aangeneem kan word dat Megasthenes op rype ouderdom ambassadeur geword het. Bowendien is van sy lewe ná sy terugkeer uit Indië niks bekend nie en is hy moontlik omstreeks 290 v.C. oorlede. Daar is in ieder geval geen bewys dat hy enige verbintenis met Alexandrië gehad het nie.

'n Mens sou kon vermoed dat die beroemde biblioteek van Alexandrië eventueel afskrifte van beide Ktesias en Megasthenes se Indika kon gehad het. Hierdie konjektuur bied egter geen lig op die ontstaan van die Septuagintvertaling van Psalm 22 nie.

Daar is tog enkele ander kultuurhistoriese gegewens wat moontlik lig op die Septuagintvertaling kan werp.

* Eerstens is daar die twyfelagtige brief van Aristeas, waarvan reeds melding gemaak is. Hy sê dat die vertaling van die Septuagint ontstaan het deur die aandrang van die bibliotekaris Demetrius en dat koning Ptolemaeus II Philadelphus self die opdrag vir die vertaling gegee het (Koole, 1961:145). Die gegewens van Aristeas moet ernstig betwyfel word. Tog kan die brief iets inhou as dit met 'n ander feit in verband gebring word, naamlik dat koning Ptolemaeus Philadelphus 'n versamelaar van plante en diere - én van vreemde literatuur was! Op grond hiervan meen Schubart (1950:280) dat die legende wat die koning met die Septuagint verbind, dalk nie heeltemal sonder grond is nie. 
- Tweedens was die renoster sedert die Hellenistiese tyd in die Ooste bekend. Later was die dier ook in die Weste in sirkusse te sien. Naas hierdie algemene inligting bied Brandenburg (1959:844) 'n brokkie informasie van besondere belang: in die praaloptogte van koning Ptolemaeus Philadelphus (regeringstyd: 285-246 v.C.) was daar ook 'n renoster ingesluit. Hieruit kan afgelei word dat die renoster vir die vertalers van die Septuagint bekend was.

\title{
8. SAMEVATTING
}

Daar is hoofsaaklik twee moontlike bronne waaruit die Septuagint se vertaling van re'em met monokeros afgelei word: die wilde stier, wat op die Ishtarpoort in Babilon afgebeeld is, of die renoster wat ten tyde van die vertaling van die Septuagint in Alexandrië bekend was. Verskeie eksegete (w.o. Van U'chelen, McCallough en Briggs) meen met meerdere of mindere mate van sekerheid dat re'em dui op die wilde stier (kyk pt. 4 hierbo). Waarom die Septuagint ten slotte re'em met monokeros vertaal het, word deur Hess (1915:121) soos volg verwoord:

\begin{abstract}
Zur Zeit der Entstehung der Septuaginta war der Wildsticr (Bos primigenius Bojanus) woh! ausgestorben, und die Uebersetzer kannten das Tier nur aus den Abbildungen, in denen es (infolge des babylonischen Stiles) nur ein Horn zu tragen scheint.
\end{abstract}

Hierdie verklaring is nie oortuigend nie. Die vertalers van die Septuagint was tog seker bekend met die tipies Babiloniese manier om afbeeldings van die sykant te gee (relieffafbeeldings), wat nie die moontlikheid laat om die twee horings van 'n dier af te beeld nie maar slegs een. Dat hulle uit die afbeelding sou aflei dat die dier gevolglik net éen horing het. lyk onwaarskynlik. Die moontlikheid dat hulle met monokeros die renoster, wat aan hulle bekend was, op die oog gehad het, lyk veel meer aanneemlik.

Die Bybeltekste waarin re'em voorkom (Num. 23:22;24:8; Deut. 33:17; Job 39:12,13; Ps. 22:22;29:6;92:11; Jes. 34:7), word deur die Septuagint konsekwent met monokeros vertaal. Die Vetus Latina het klaarblyklik die Septuagint gevolg en re'em (resp. monokeros van die LXX) konsekwent met unicomis vertaal. Daarenteen het die jonger Griekse vertaling van Aquila re'em met rhinokeros weergegee. Hieruit kan ons aflei dat hy die Hebreeuse re'em met die renoster geïdentifiseer het. Dit bevestig die moontlikheid wat in die vorige paragraaf as verklaring voorgestel is.

Die Luthervertaling en die Statevertaling kom ooreen met die Septuagint en die Vetus Latina deur re'em met eenhoring te vertaal. Die Vulgaat daarenteen is nie konsekwent nie maar vertaal re'em (resp. monokeros) afwisselend met rhinoceros, monoceros en unicomis, sonder dat die teksverband in die betrokke tekste daartoe aanleiding gee. Hoe weinig daar ' $n$ verskil in betekenis tussen die drie laasgenoemde woorde aangevoel is, blyk uit die werk van Hiëronimus self. In die Vulgaat word re'em in Psalm 28:6 
(ons vert. Ps. 29:6) met unicornis vertaal. In Hiëronimus se Psallenium iuxta Hebraeos word dieselde Hebreeuse woord egter met rhinoceros vertaal. In die Jobkommentaar van een van Hiëronimus se leerlinge word rhinoceros, monoceros en unicomis duidelik afwisselend gebruik ${ }^{2}$ (vgl. vir bogenoemde gegewens en dokumentasie die verskillende Bybelvertalings en Brandenburg, 1959:844-845). Hierdie feit versterk ook die verklaring waarom die Septuagint re'em met eenhoring (= renoster) vertaal het.

\section{GEVOLGTREKKINGS}

* In die inleiding is gemeld dat die eenhoring danksy die New Age tans weer 'n bekende simbool is. Die aanhangers van die New Age het die simbool van die eenhoring nie primêr uit die Laat Middeleeuse kuns geput nie maar uit Oosterse gegewens. Tog is daar 'n voorbeeld in 'n New' Age-geskrif waar een van die tarotkaarte met die Middeleeuse opvatting in verband gebring word. Tarotkaarte is 'n stel van 22 geïllustreerde kaarte waarmee voorspellings gemaak word (Chandler, 1989:359). Onder hulle kom die vroulike pous voor, en sy is volgens legende "the virgin who tames the unicorn" (Cavendish, 1988:71). Origens word die eenhoring as kragdier aan die Ooste ontleen, hoewel dit gewoonlik (ook in kunswerke) as 'n kleinerige dier geskets word. In die kommersiële wêreld is dit 'n perdjie met 'n kort horinkie op die kop wat as "my klein ponie" vir kinders verkoop word (De la Guerre, 1991:80, met afb.). Die eenhoring word selfs as 'n heilige dier voorgestel (verw. by De la Guerre, 1991:81). Hierdie opvatting kom uit die Ooste; die eenhoring was immers 'n heilige dier in die Sjinese mitologie (Rall-Niu, 1980:143-144). Ofskoon die enkele sinspeling op die Middeleeuse tradisie, is dit duidelik dat die eenhoringsimbool van die New Age in wese niks met die Christelike tradisie en met die Bybelse 'eenhoring' te doen het nie.

- Die vertalers van die Septuagint was reeds so lank in die verstrooing dat hulle nie meer die betekenis van re'em geken het nie.

- Omdat re'em in die Ou Testament 'n dier met brute krag simboliseer, het die vertalers van die Septuagint dit met monokeros vertaal. Daarmee het hulle heel waarskynlik die renoster, wat by hulle bekend was, bedoel.

- Die vertalers van die Septuagint doen dus dieselfde as wat Aquila in sy later Griekse vertaling doen: om re'em met renoster weer te gee. Die vertalers van die Septuagint noem die renoster egter monokeros, terwyl Aquila dit rhinokeros noem. Of daar 'n verandering in woordgebruik (van monokeros na rhinokeros) sedert die Septuagintvertaling tot by Aquila se vertaling plaasgevind het, is nie bepaalbaar

2 'numquid solet rhinoceros servire tibi' ... Sive ut alii dixerunt: 'numquid volet monoceros servire tibi?' Ex diversa edilione transferentium advertimus, quod ipsum sit rhinoceros quod et monoceros, et Latine inlelligatur unicornis, sive super nares cornu habens. 
nie. In ieder geval pleit die latere Vulgaat se sinonieme gebruik van die woorde dat daar geen verskil was nie.

* Ktesias en Megasthenes se fabelagtige beskrywing van die Indiese eenhoring kom nie in aanmerking as bronne van of invloed op die Septuagintvertaling nie.

- Omdat die Bybelvertalings die eenhoring met die renoster identifiseer, kon die Physiologus, 'n Christelike geskrif uit omstreeks 200 n.C., allerlei fabelagtige verhale oor die vangs van die renoster op die eenhoring oordra. In hierdie geskrif word die eenhoring, hoewel gewoonlik geassosieer met 'n kragtige dier, voorgestel as so klein soos 'n bokkie wat in die skoot van 'n maagd kan spring en deur haar gesoog en getem kan word (Brandenburg, 1959:851-852). Die Physiologus was die bron van die later Middeleeuse voorstellings van die eenhoring.

- Luther het hom nie aan die voorstellings van sy tyd (bv. die bekende tapisserie Die dame met die eenhoring) gesteur nie maar die Septuagint (of die sinonieme van die Vulgaat?) gevolg en die eenhoring as magsdier vir re'em in die betrokke tekste weergegee.

- Die Bybelvertalers (van die Septuagint tot by Luther en die Statevertaling) het dus nie bedoel om met eenhoring na 'n fabeldier te verwys nie maar na 'n dier wat werklik bestaan (hoogs waarskynlik die renoster). Afgesien van die oordrewe beskrywings van Ktesias en Megasthenes was dit deur die Physiologus dat die eenhoring as 'n klein bokkie sy fabelagtige aard bekom het; tog is daar nie aan die bestaan van die fabelagtige dier getwyfe! nie. Ambrosius (339-397) was 'n uitsondering deur sy opmerking dat die eenhoring volgens kenners nie onder die diersoorte voorkom nie; ná hom was dit eers weer Marco Polo (1254-1324) wat vol verbasing gesê het dat die massiewe renoster van Sumatra nie pas op die eenhoring in die skoot van 'n maagd nie (Einhorn, 1981:1246).

\section{BIBLIOGRAFIE}

\section{Bybels}

Biblia Hebraica 1951. Edidit R. Kittel. 10de dr. Stuttgart : Priviligierle Wurtembergische Bibelanstalt. Biblia sacra iux1a vulgatam versionem 1975. 2de dr. Stuttgart: Wurtembergische Bibelanstalt.

Bijbel 1899. Door last van de hoog mog. heeren Staten Generaal der vereenigde Nederlanden. Londen : Britsche en Buitenlandsche Bijbelgenoolschap.

Die Bihel 1899. In Dr. Luthers Uebersetzung. Konstanz : Christlicher Buch- und Kunstverlag K. Hirsch.

Die Bybel 1957. 4de uitg. Kaapstad : Bybelgenootskap van Suid-Afrika

Die Bybel 1984. Nuwe vertaling. 3de dr. Kaapstad : Bybclgenootskap van Suid-Afrika. Septuaginta 1935. Edidit A. Rahlfs. Ed. nona. Stuttgart : Deutsche Bibelstiftung.

The Bible 1972. Authorised Version. Oxford: The Bible Societies 


\section{Ander bronnc}

ANON. 1957. Eenhoorn. (In Christelijke encyclopedic 2:548.)

ANON. 1972. Ecnhoring. (In Ensiklopedic van die wčreld 3:642.)

ANON. 1890. Einhorn. (In Meyers Konversations-Lexikon 5:382.)

BRANDENBURG, H. 1959. Einhorn. (In Reallexikon für Antike und Christentum 4: kol. 840-862.)

BRIGGS, C.A. 1969. The Book of Psalms, vol. 1. (I.C.C.) Edinburgh : Clark.

CALVYN, J. 1979. Commentary on the Book of Psalms, vol. 1. Transl. by H. Beveridge. Grand Rapids : Baker. (Calvin's commentaries, vol. 4.)

CAVENDISH, R. 1988. The Tarot. Repr. London: Chancellor Press.

CHANDLER, R. 1989. Understanding the New Age. Milton Keynes: Word Publishing.

CLARK, Bill. 1984. The Biblical Oryx - A New Name for an Ancient Animal. Biblical Archoeology Review, 10(5):66-70.

DAVIDSON, B. 1945. The Analyical Hebrew and Chaldee Lexicon. London : Bagster \& Sons.

DE LA GUERRE, F.J. 1991. Elke New Age knie sal buig. Porchefstroom : De la Guerre.

DIJKSTRA, K. 1982. Christclijke symbox)liaal. Baarn : Bosch \& Keuning.

EINHORN, J.W. 1981. Einhorn. (I/f Enryklopadic des Marchens 3: kol. 1246-1256.)

FERGUSON, G. 1961. Signs \& Symbols in Christian Art. London : Oxford University Press.

GORDON, C.H. 1965. Ugaritic Textbook. Roma : Pontificium Institutum Biblicum. (Analecta Orientalia, 38.)

GROENEWEGEN-FRANKFORT, H.A. \& ASHMOLE, B. s.j. Arl of the Ancient World. Englewood Cliffs : Prentice Hall.

HESS, J.J. 1915. Beduinisches zum Alten und Neuen Testament. Zeitschrift für die Alttestamentliche Wissenschafl, 35:121-123.

HUYGHE, R.ed. 1970. Larousse Encyclopedia of Prchistoric and Ancient Art. London: Hamlyn.

ISAACS, J. 1940. The Authorized Version and after. (In Robinson, H.W. ed. The Bible in Its Ancicnt and English Versions. Oxford : Clarendon.)

JACOBY, F. 1922. Kıesias. (In Paulys Realencyclopadic der classischen Altertumswisscnschaft 11,2: kol. 2032-2073.)

KLOTZ, J.W. 1979. The Lion and the Unicorn. Concordia Joumal, 5(6):213-215.

KOOLE, J.L. 1961. Septuaginta. (In Christelijke encyclopedic 6:145-147).

LIVESEY, R. 1988. More Underslanding Alternative Medicinc. 3rd. ed. Chichester : New Wine Press.

MCCAllOUGH, W.S. 1955. The Psalms. (Interpreler's Bible).

RALL-NIU, J. 1980. Drachen, Phoenix, Einhorn und Schildkrote, die vier heiligen Tiere in der chinesischen Mythologic. Symbolon, 5:143-151.

SCHUBART, W. 1950. Alexandria. (In Reallexikon für Antike und Christentum 1: kol. 271-283.)

STEIN, O. 1931. Megasthenes. (In Paulys Realencyclopädie der classischen Altertumswissenschaft 15,1: kol. 230-326.)

STOKER, H.G. 1935. Uitlegging of interpretasic. Koers, 2(5):27-33. April.

STRONG, D.E. 1965. The Classical World. London : Hamlyn.

TIMMERS, J.J.M. 1985. Christelijke symboliek en iconografic. 5de dr. Wecsp : De Haan.

VAN UCHELEN, N.A. 1971. De Psalmen, decl 1. Nijkerk : Callenbach. (De prediking van het Oude Testament.)

WELlmaNN, M. 1905. Einhorn. (In Paulys Realencyclopadic der classischen Altertumswissenschaft 5,2: kol. 2114-2115.)

WITTKOWER, R. 1976. Allegory and the Migration of Symbols. London : Thames \& Hudson. 
